\title{
VENEREAL DISEASES AND LIFE ASSURANCE *
}

\author{
By L. W. HARRISON
}

WITH your permission, I will limit this paper to syphilitic and gonococcal infections. Another venereal disease, lymphogranuloma inguinale, may shorten life but it must affect few or no proposers for life assurance and is unlikely to interest you. I will start with gonorrhœa because it is most easily disposed of.

It is admitted that gonorrhœa can cause myocardial and endocardial lesions, but with due allowance for cases being overlooked at the time of the gonococcal infection it is difficult to believe that any residua of this kind would escape notice at the time of the medical examination. The same applies to the rare renal and nervous complications which occasionally occur in gonorrhœa, and the only residua of gonorrhœa which seem to be worthy of any discussion in the present case are stricture of the urethra and fibrous prostate.

As regards stricture of the urethra, I think every genito-urinary surgeon will agree that, contrary to experience twenty or more years ago, this condition is now a relatively rare sequel of gonorrhœa. This is thanks mainly to the mildness of local applications in modern treatment and perhaps also to the care over tests of cure.

For information on the significance of fibrous prostate I am relying on a paper by Mr. Kenneth Walker (I936) in judging that it is also very uncommon in relation to the frequency of gonorrhœa and that it must be a rare shortener of life. I ought to qualify all this by saying that Mr. Walker's article did not give statistics, but the strong impression that the condition is relatively uncommon is supported by his statement that it is frequently associated with stricture and by the following paragraph with which the article ended.

"Mention has been made in this article of the diminished frequency of stricture as the result of an improvement in the

* An address to the Assurance Medical Society on Feb. 7th, 1940. 


\section{BRITISH JOURNAL OF VENEREAL DISEASES}

general level of treatment of gonorrhœa. It is possible that subsequent years will show a fall in the incidence of obstruction from the fibrous prostate. If this be so, it will be difficult for any genito-urinary surgeon to write an article on the sequelæ of chronic gonorrhœa."

Altogether I suggest that an admission of gonorrhœea in the past should not call for penalties provided that there is an assurance that no stricture has been left.

As regards syphilis, nearly thirteen years ago when I had the honour of addressing you on the prognosis of syphilis, I concluded as follows :-

"I have attempted to show in this paper :-

“ (I) That by earliest possible treatment on well conducted lines a syphilitic infection can be eradicated in almost all cases, and that therefore the expectation of life is diminished only slightly."

" (2) That in a stage a little later than this, but within six months of infection, one can safely expect eradication in 75 per cent. of cases."

" (3) That these results contrast with those obtained in the preSalvarsan era when cure of syphilis in the sense of eradication was probably effected in only a negligible proportion of cases."

" (4) That in cases of older standing it is reasonable to expect that, by timely treatment, a very considerable proportion of disease of vital organs for which syphilis has gained its reputation as a killing disease of a very high order can be prevented."

" (5) That the outlook in the worst event, the onset of general paresis, has been improved considerably by malarial treatment."

"By inference from these conclusions it is clear that, in assessing the risk from a syphilitic infection, the medical adviser must consult the record as to treatment and serological examination, and must know the present state of the blood serum, if not also that of the spinal fluid. With this information in his possession and a report on the state of the vital organs, as judged by a very careful clinical examination, it should be possible to assess the risk with greater fairness to the candidate or the company than was ever possible before the advent of our modern methods."

Probably these conclusions were not sufficiently definite to satisfy many of those present but I still cannot think that any closer general advice was possible at that time.

The question now is, have we acquired any more helpful information since 1927? I hope to show that we have and that although much of it is by no means so precise as could be wished, it does suggest that in certain well-defined conditions assurance companies run 
practically no risk in accepting without additional premiums proposers who admit a syphilitic infection.

The available information is of three kinds :-

(I) The after histories in respect of development of cardio-vascular and neuro-syphilis of patients who have received varying amounts of treatment.

(2) The histories, in respect of treatment given in the earlier stages of their infections, of patients suffering from parenchymatous neuro-syphilis and from cardio-vascular syphilis.

(3) The effect of treatment on the late effects just mentioned.

I think that the first and second of these methods of investigation in spite of their defects should show that it is relatively easy to prevent life-shortening effects of syphilis, and the third that, when cardio-vascular or neuro-syphilis has unfortunately occurred, life can often be prolonged substantially.

The method of analysing the records of patients who have received certain amounts of treatment to see what proportion of them developed life-shortening complications has the defect that only a relatively small percentage of the original patients are ever examined sufficiently long after the original treatment to enable a judgment of the outcome to be formed, and one must then decide whether or not those who are examined later are a fair sample of the original group. Most workers seem to agree that this follow-up method usually shows results of treatment at their worst because patients with relapses are more likely to return to medical observation than those who remain well. I believe that this is generally the case and that it probably applies to women more than to men; the tendency of women to neglect attendance for further observation so long as they are well may explain the fact of their showing in such statistics a higher proportion of late effects than one would judge actually occurs.

Sometimes the follow-up method seems to show results in a better light than seems credible as I believe was the case in some of Bruusgaard's well-known statistics which I must discuss here if only to escape the reproach of having overlooked them.

Probably no modern paper on prognosis of syphilis 


\section{BRITISH JOURNAL OF VENEREAL DISEASES}

would be regarded as complete without some reference to Bruusgaard's statistics because they have been so extensively quoted as showing better than any other what happens when syphilis is not treated with any specific remedy. I believe they have serious limitations in this respect and am in fact relieved that it does not seem necessary to discuss the outlook in untreated syphilis. I cannot, however, dismiss them without giving reasons for this view because in at least one important investigation they have been used as a basis for comparison with figures relating to results of treatment.

Bruusgaard's paper published in I929 dealt with the after-histories of the cases of early syphilis that attended the clinic of Cæsar Boeck, Oslo, during the twenty years from I89I to I9Io, and its special interest lay in the fact that the patients had received no specific treatment whatever. The total number of cases was 2,I8I (I,388 females and 793 males), and Bruusgaard investigated their later histories from 3 to 36 years after infection. Altogether he traced 309 patients who were still alive and I64 who had died, a total of 473 classified as follows:-

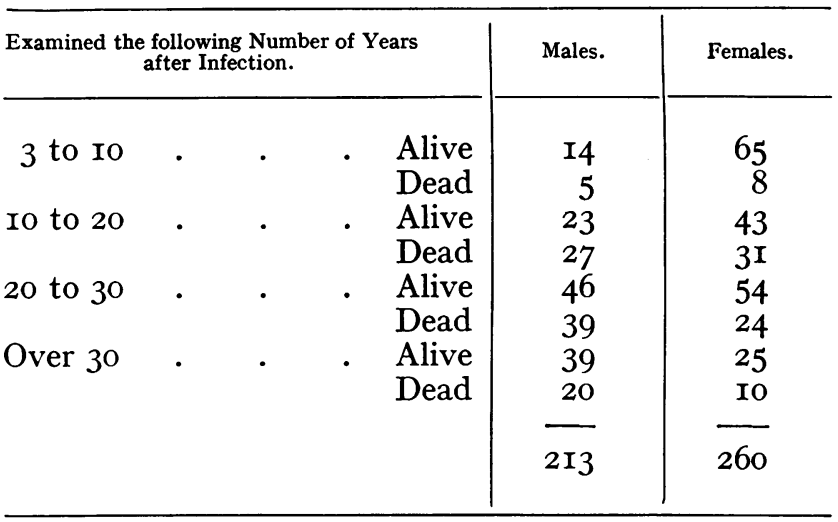

Of the above number of live patients who were examined, only those with infections of over I5 years' duration were called up for re-examination ; the group with more recent infections who were examined comprised only those patients who had returned to the policlinic or to the Ulevaal Hospital, Oslo, for treatment. They are therefore a selected group who might be expected to show a higher proportion of relapses than the original group of cases dealt with 3 to 15 years previously; 
on the other hand, as they contained a number observed for less than ro years, they might be expected to show a lower proportion of cardio-vascular and neurosyphilis than would cases with older infections. One result of Bruusgaard's analysis has been much quoted and rather surprising conclusions drawn from it, though in my view this is the feature which demonstrates the weakness of the whole series as a guide to the prognosis of untreated syphilis. It is the very small number of cases of G.P.I. that were discovered, viz. I3. Bruusgaard stated his belief that this number represented the total which occurred in the whole 2,I8I original cases because the records of the institutions in Oslo to which they would probably be admitted were searched, and he therefore concluded that the incidence of G.P.I. in Boeck's cases had been $0 \cdot 6$ per cent.

This surprisingly low percentage of G.P.I. in Boeck's untreated cases naturally excited great interest at the time Bruusgaard first published his paper, and it was even compared by one learned English writer with the 4 or the 2 per cent. which he suggested occurred in treated cases as evidence that " the outlook of a patient who has had no specific treatment may be actually better than that of one who has been through the orthodox course." Apart from the fact that the vast majority of cases of G.P.I. have never been treated in the early stages of their syphilis and therefore that a comparison of Bruusgaard's 0.6 per cent. with whatever figure you may accept as the average percentage of G.P.I. in syphilis is not a comparison of results of no treatment with results of orthodox treatment, the figures are very strong evidence that either Bruusgaard missed a substantial number of the cases of G.P.I. that occurred in Boeck's series or all our ideas respecting the lower incidence of G.P.I. in syphilitic females than in syphilitic males are wrong. The distribution of the cases by sexes shows 8 females and 5 males, which make 0.57 per cent. of the original females and 0.63 per cent. of the original males. In the cases which were actually followed up for more than Io years or died the percentage incidence of G.P.I. was actually greater in the females than in the males. If this was really the case in the general population of syphilitics, we should have to believe that the incidence of syphilis in males in Norway was over four 


\section{BRITISH JOURNAL OF VENEREAL DISEASES}

and a half times the incidence in females because in the years I9I4 to I928 the deaths from G.P.I. in Norway were 472 males and I05 females, a ratio of 4.6 to I. The evidence from Norwegian statistics, from the more reliable statistics of infections in Sweden and from other sources suggests strongly that the ratio of syphilitic infection of males to syphilitic infection of females in Norway was no higher than 2 to I, and many workers would put it lower than this.

Another point of interest in Bruusgaard's statistics relates to the number of cases found in later years to have no sign whatever of syphilis. The numbers were I32 living patients with no sign and negative Wassermann reactions and I4 dead of cancer or of tuberculosis more than 20 years after infection in whom autopsy revealed no sign of syphilis. These figures have been quoted as evidence of spontaneous recovery from syphilis, but they would have carried more weight if the original diagnosis had been supported by laboratory tests. Most of these cases were dealt with first in Boeck's clinic before the advent of laboratory aids, and we know how often in that era the very elect were mistaken. I do not say that the I32 and the I4 did not suffer from syphilis but that in most of them the infections were non-proven according to modern standards of diagnosis. For the reasons which I have given I do not propose to make any use of Bruusgaard's figures.

As regards the effects of treatment, by far the most comprehensive and searching investigation extant is known as the "Co-operative Clinical Studies in the Treatment of Syphilis " which was started in U.S.A. a little over ten years ago by a committee composed of directors of five important clinics and four representatives, including a statistician, of the U.S. Public Health Service, which we now know as the Co-operative Clinical Group, or the C.C.G. The original material on which the C.C.G. started work consisted of the records of 75,000 cases of syphilis in all stages that had been dealt with in the five clinics in the previous 15 years. This material was broken up into a number of categories according to stages of syphilis, amounts of treatment administered, length of observation and so forth, a large number being thrown out because of insufficient observation, and from I93I to I 938 papers on the response to 
treatment of patients in different categories have been published. The results of chief interest to us here relate to the outcome in respect of disastrous late effects in cases who had received in the early stages of their infection the standard treatment now recommended by the C.C.G. and had been observed afterwards for 3 to 20 years ; I may say here that the papers I am quoting show that all resources of modern medicine were employed in the examination of these cases. The first I will discuss is one by Vonderlehr and Usilton published in November 1938 and dealing with patients observed for 3 to Io and Io to 20 years after treatment ranging from none to the minimum of 20 arsphenamine injections with corresponding heavy metal which the C.C.G. have recommended as standard. Table I, adapted from one of Vonderlehr and Usilton's, shows the results of chief interest to us here. The section of chief importance consists of 6r patients who had received

TABLE I.-Outcome in cases of syphilis receiving "less than standard" and "standard" treatment* respectively in the early stages of infection (adapted from paper by Vonderlehr and Usilton, I938).

\begin{tabular}{|c|c|c|c|c|c|}
\hline \multirow{3}{*}{\multicolumn{2}{|c|}{ Status when Last Examined. }} & \multicolumn{4}{|c|}{ Observation Periods. } \\
\hline & & \multicolumn{2}{|c|}{3 to to Years. } & \multicolumn{2}{|c|}{ to to 20 Years. } \\
\hline & & $\begin{array}{l}\text { Less than } \\
\text { Standard } \\
\text { Treatment } \\
\text { (848 Cases). }\end{array}$ & $\begin{array}{c}\text { Standard } \\
\text { Treatment } \\
\text { (504 Cases). }\end{array}$ & $\begin{array}{l}\text { Less than } \\
\text { Standard } \\
\text { Treatment } \\
\text { (191 Cases). }\end{array}$ & $\begin{array}{l}\text { Standard } \\
\text { Treatment } \\
\text { (6r Cases). }\end{array}$ \\
\hline $\begin{array}{l}\text { Neuro-syphilis : } \\
\text { Srmptomatic }\end{array}$ & & Per cent. & $\begin{array}{l}\text { Per cent. } \\
0.6\end{array}$ & Per cent. & Per cent. \\
\hline Asymptomatic & . & $4 \cdot 6$ & $2 \cdot 6$ & $5 \cdot 7$ & $\mathrm{I} \cdot 6$ \\
\hline \multicolumn{6}{|l|}{ Cardio-vascular: } \\
\hline Definite & . & $\mathrm{I} \cdot 4$ & $I \cdot 2$ & $5 \cdot 8$ & o \\
\hline Possible & . & $0 \cdot 6$ & $0 \cdot 2$ & $2 \cdot I$ & $4 \cdot 9$ \\
\hline Skin, Mucosal an & oone & $2 \cdot 4$ & $0 \cdot 4$ & $I \cdot 6$ & o \\
\hline Visceral . & . & $\mathrm{O}$ & o & 0.5 & o \\
\hline Ocular & . & 0 & 0 & $0 \cdot 5$ & 0 \\
\hline \multicolumn{6}{|l|}{ Symptom-free : } \\
\hline Positive blood & . & $19 \cdot 5$ & $7 \cdot 7$ & I7 3 & $6 \cdot 6$ \\
\hline Negative ,, & . & $67 \cdot 4$ & $87 \cdot 3$ & $56 \cdot 0$ & $85 \cdot 3$ \\
\hline
\end{tabular}

* Standard treatment $=20$ or more doses of arsenical compound plus heavy metal.

Less than standard treatment $=$ less than above, or above given irregularly. 


\section{BRITISH JOURNAL OF VENEREAL DISEASES}

the standard treatment and had been observed for ro to 20 years. In this group the incidence of symptomatic neuro-syphilis was $I \cdot 6$ per cent. and there was no definite case of cardio-vascular syphilis though 4.9 per cent. were marked as possibly having this manifestation. The percentage completely free from all signs, whether clinical or in blood or spinal fluid, was 85.3 , and those not completely normal comprised 6.6 per cent. with positive blood and $\mathrm{r} \cdot 6$ per cent. with positive fluid but without any clinical sign.

In the group observed for 3 to Io years were 504 patients who had received the standard treatment of 20 arsenical injections plus corresponding heavy metal and the percentage free from all signs was $87 \cdot 3$. Those not regarded as free from syphilis comprised 0.6 per cent. with symptomatic neuro-syphilis, $\mathrm{I} \cdot 2$ per cent. with definite and 0.2 per cent. with possible cardio-vascular syphilis, 0.4 per cent. with signs in skin, mucous membranes or bones, $7 \cdot 7$ per cent. with positive blood and $2 \cdot 6$ per cent. with positive fluid.

Altogether in these two groups of cases which had received 20 or more injections of arsphenamine the most searching tests with full use of modern equipment appear to have discovered no more than $\mathbf{2 \cdot 2}$ per cent. of symptomatic neuro-syphilis and $\mathrm{I} \cdot 2$ per cent. of definite cardiovascular syphilis with life-shortening possibilities.

It is convenient here to deal with older cases of syphilis of more than four years' duration with positive blood but no clinical sign of syphilis and negative spinal fluid; cases of asymptomatic neuro-syphilis will be discussed later. The best evidence of the outlook in such cases is that contained in the paper on latent syphilis by Moore and colleagues of the C.C.G., in which treated cases observed for ro or more years showed satisfactory results, cure or arrest, in 85 per cent., and of the balance 12.5 per cent. were unsatisfactory only in respect of the blood reactions. When the period of observation was less the results obtained so far in 287 cases had apparently not been so good, showing $5 \cdot 2$ per cent. of clinical relapse and $3 \mathrm{I} \cdot 7$ per cent. still Wassermann positive. The study showed also the tendency of latent syphilis to arrest or cure, as appeared to be demonstrated also by Bruusgaard's statistics. On this tendency to spontaneous cure or arrest I think most workers with experience of latent 
syphilis will find supporting evidence in their own cases which have become completely negative in a number of years after prolonged treatment has been suspended. With regard to the nature of any clinical relapse to be expected in latent cases with negative spinal fluid, there is general agreement that the probability of its occurring in the central nervous system is very remote.

In regard to percentages of late clinical relapse, whether in cases followed up from treatment in the early stages or in those treated first in the latent stages, it must be remembered that they do not by any means represent cases of premature death. I will deal with the possibilities of preventing or postponing death in such cases as also in the other cases presenting no clincial sign or only doubtful ones presently, but before doing so I should like to discuss the question whether results as good as, or better than, those reported as following so-called standard treatment in U.S.A. may be expected from the treatment practised by leading syphilologists in this country.

Admittedly it is difficult to compare closely the results obtained in this country with those of the C.C.G. because observation has not been so prolonged in so many cases and cases have not perhaps been searched so thoroughly for signs of cardio-vascular or neurosyphilis as appears to have been the case in the C.C.G.'s series, but it seems fair for the present purpose to compare the clincial relapses of a secondary syphilitic type following the standard U.S.A. treatment with those reported after treatment according to the best schemes practised in this country; they ought to show how the ultimate results of the latter would compare with those reported by the C.C.G. I believe this to be fair because within limits comparisons have shown percentages of mucocutaneous relapses to be inversely proportional to the efficiency of treatment; as an example, in a paper entitled "What Treatment in Early Syphilis Accomplishes," by Stokes and Usilton with colleagues (I934), which was based on the C.C.G.'s collection of cases, their Table II shows muco-cutaneous relapses as follows. After 9 or less doses of arsphenamine, $7 \cdot 7$ per cent.; after Io to I9 doses, $4^{\circ} 0$ per cent. ; after 20 to 29 doses, 3.6 per cent.; after more than 30 doses, $\mathrm{I} \cdot \mathrm{I}$ to $\mathrm{I} \cdot 2$ per cent. These results are summarised in Table II. With the 
TABLE II.-Clinical relapses of early type in cases receiving different amounts of treatment, reported by Stokes, Usilton et al. Co-operative Clinical Group, U.S.A. (I934).

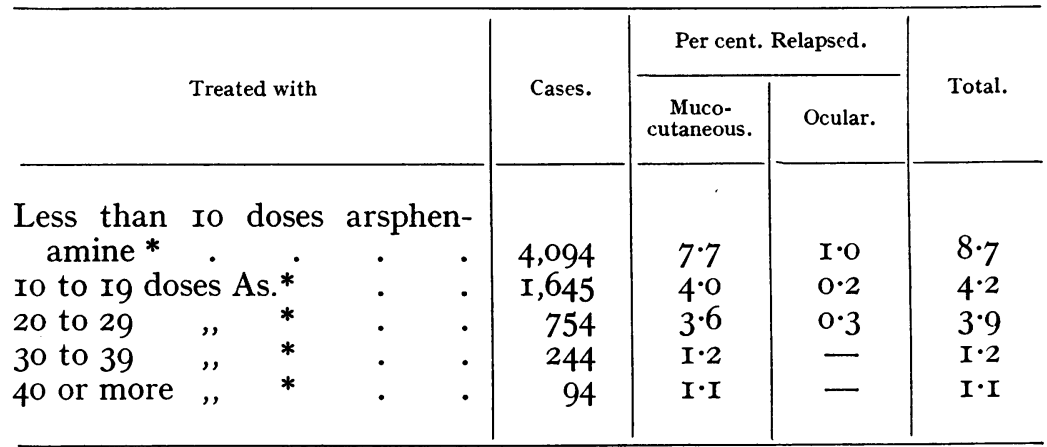

* Presumably $\mathrm{Bi}$ or $\mathrm{Hg}$ also given.

3.6 per cent. of muco-cutaneous relapses in 754 cases of early syphilis treated with 20 to 29 doses of arsphenamine with corresponding heavy metal may be compared the following which have been reported in Great Britain. They suggest strongly that the ultimate outcome in cases which have received full treatment on lines customary in good clinics in this country will prove to be as good as in the C.C.G.'s cases. Snodgrass and Peters (r937) in 395 cases described as having received in Glasgow an adequate first course of treatment (whatever more they. had) consisting of Io doses of neoarsphenamine concurrently with Io of mercury or of bismuth administered in 15 weeks reported 2.8 per cent of clinical relapse. In I929 I published as a M.R.C. Special Report an analysis of records of early cases of syphilis which showed relapses after varying amounts of treatment. At a later date I had the records brought up to date with the object of publishing a later report. This has not yet proved possible but I have been able to search the records for clinical relapses, and in I70 cases which had been treated with two or more regular courses of injections, i.e. 20 or more injections of each type of remedy given concurrently, the number of clinical relapses discovered in observation periods ranging from three months to eleven years was three, of which two occurred in one patient; the percentage of mucocutaneous relapses in this series was thus $I \cdot 7$. 


\section{VENEREAL DISEASES AND LIFE ASSURANCE}

Good as these results are they are surpassed by those reported in recent published correspondence by directors of four important clinics all of whom claimed a cure rate of roo per cent., or practically this, from schemes of treatment consisting of three to four courses each of neoarsphenamine or equivalent concurrently with bismuth. As an example may be quoted the scheme recommended by Batchelor and Lees which consists of four unit courses of neoarsphenamine and bismuth with an interval of four weeks between any two courses. In each course, which lasts Io weeks, are administered 6.I5 grm. neoarsphenamine in $\mathrm{I} 2$ injections concurrently with $2.9 \mathrm{grm}$. bismuth in Io injections. The authors stated that the relapse rate in 675 male cases of early syphilis treated in the Edinburgh clinic by this scheme had been 0.9 per cent. It is not the purpose of this paper to discuss details of treatment, but it may be permissible to mention here that the British schemes of treatment which I have quoted differ from that affording best results in U.S.A. in giving the arsenical and heavy metal preparations concurrently, in allowing an interval between courses and in the heavier dosage of the bismuth component. The minimum amount is now usually from 30 to 40 injections of each type of remedy.

The British schemes which I have just quoted as giving approximately Ioo per cent cures differ from the earlier ones by Snodgrass and Peters and at St. Thomas's Hospital by their greater intensity and for the most part by the shorter interval between courses; this shorter interval of one month in place of two or three was recommended by the League of Nations Committee of Experts. It is a compromise between the old intermittent scheme and the completely continuous one which is so greatly favoured in U.S.A. Altogether I feel sure that we are justified in regarding the prognosis in cases treated on the best schemes in this country as being quite as favourable as that of cases treated by the standard C.C.G. plan the ultimate results of which I have quoted.

So far I have shown that, as judged by results of treatment ascertained by testing as many patients as possible after given amounts of treatment, a method of investigation which probably shows treatment in its worst light, modern treatment in the early stages can 


\section{BRITISH JOURNAL OF VENEREAL DISEASES}

reduce the risk of serious late effects of syphilis to quite negligible proportions.

I should like now to view the problem from the other end. What proportion of patients with serious late effects of syphilis received amounts of treatment which are now regarded as minimal? On this branch a number of papers are available and in each of them one fact which stands out with monotonous regularity is the very low proportion of cases with either cardiovascular or neuro-syphilis who in the early stages of their infections received more than ten injections of an arsphenamine preparation with bismuth or mercury. In the papers by seven groups of authors which I have studied are particulars, summarised in Table III, of the early treatment of $\mathrm{I}, 086$ cases of G.P.I., tabes and taboparesis, and of 222 cases of cardio-vascular syphilis, and in these the numbers stated to have received adequate

TABLE III.-Treatment in early stages of infection in cases of Cardio-vascular Syphilis, General Paresis, Taboparesis and Tabes Dorsalis.

Total cases investigated and those described as having been treated properly in early stages of infection.

\begin{tabular}{|c|c|c|c|c|c|}
\hline \multirow{2}{*}{ Authors *. } & \multirow{2}{*}{$\begin{array}{l}\text { Cardio- } \\
\text { vascular. }\end{array}$} & \multicolumn{2}{|c|}{$\begin{array}{l}\text { Central Nervous } \\
\text { System. }\end{array}$} & \multirow{2}{*}{$\begin{array}{c}\text { Total } \\
\text { Investi- } \\
\text { gated. }\end{array}$} & \multirow{2}{*}{$\begin{array}{l}\text { Total } \\
\text { Classed as } \\
\text { Properly } \\
\text { Treated } \\
\text { in Early } \\
\text { Stages. }\end{array}$} \\
\hline & & $\begin{array}{c}\text { G.P.P. } \\
\text { and Tabo- } \\
\text { paresis. }\end{array}$ & Tabes. & & \\
\hline \multirow{8}{*}{$\begin{array}{l}\text { A. Müller-Dehan (I928) } \\
\text { D. C. Smith \& R. D. Kimbrough } \\
\text { (I928) } \cdot \text {. } \\
\text { F. E. Weatherby (I929) } \\
\text { J. F. Madden (I930) } \\
\text { P. A. O'Leary \& J. R. Rogin } \\
\text { (I932) . } \\
\text { J. Strandberg (I937). } \\
\text { W. P. Thompson, W. J. Comeau } \\
\text { and P. D. White (I939). }\end{array}$} & IOO & - & 一 & IOO & I \\
\hline & 56 & 一 & 一 & 56 & $\mathrm{O}$ \\
\hline & - & I35 & $3 I$ & I66 & 2 \\
\hline & 40 & I57 & I38 & 335 & 2 \\
\hline & - & 77 & 219 & 296 & 3 \\
\hline & - & 254 & 75 & 329 & 6 \\
\hline & 26 & - & - & 26 & 2 \\
\hline & 222 & 623 & 463 & $\mathrm{I}, 308$ & I6 \\
\hline
\end{tabular}

* Figures given in this table do not include all cases reported on by authors quoted. Meningo-vascular cases excluded on account of difficulty of distinguishing in any brief form early from late cases. 
treatment, so-called, in the early stages of their infection are $I 6$, or $I .5$ per cent. The details of the papers show that these are maximal figures because some of the cases classified as having had adequate treatment had received no more than Io injections.

Quite probably I have omitted mention of some important papers, but I cannot believe that those authors whose papers I have consulted on this point would have omitted mention of any work which contradicted their own findings, and it seems justifiable to conclude that this evidence supports strongly that which is derived from study of after-histories of patients who have received prescribed treatment that cardio-vascular syphilis and late neurosyphilis occur in only a negligible proportion of cases treated properly in the early stages of their infection.

I propose a little later to offer evidence, in death rates from G.P.I., tabes and aneurysm, that a comparatively small amount of treatment must suffice to prevent these late effects in a large proportion of cases, but first I would like to discuss the prospects of postponing death when signs of neuro-syphilis or of cardio-vascular syphilis are discovered, and will start with neuro-syphilis.

In connection with the question of syphilitic life-policy holders dying prematurely of neuro-syphilis it seems particularly important here to stress the possibilities of arresting the disease before clinical signs have made their appearance. Private experience supports that which has been published by many authors in showing that, whereas the trivalent arsenical remedies commonly fail to influence late syphilitic activity in the central nervous system, as judged by changes in the spinal fluid and by the occasional development of G.P.I. in patients on full treatment by this class of remedy, treatment by such pentavalent arsenical remedies as tryparsamide, in conjunction with bismuth, and by pyrogenetic methods when injection treatment does not appear to be affecting the changes in the spinal fluid has a most powerful effect. As I shall show in more detail presently, the evidence suggests that we can prevent the development of symptomatic neurosyphilis in the very great majority of cases by timely treatment in the asymptomatic stages.

I hope to show also that when matters have gone further than this and symptoms of late neuro-syphilis have appeared the outlook is still good. 


\section{BRITISH JOURNAL OF VENEREAL DISEASES}

As regards late asymptomatic neuro-syphilis, statistical evidence showing closely the proportion of cases of late latent syphilis with positive spinal fluid in which complete reversal and improvement respectively may be expected from pyrogenetic treatment is not easy to collect because much depends on the length of observation after the treatment. It is well known that reversal of spinal fluid changes is slow and no close conclusions can be drawn from the results of tests carried out less than about two years after the cure. This probably explains the differences in statistics. In spite of their limitations, however, the results obtained by different workers show that by pyrogenetic treatment one succeeds in effecting a very marked improvement of the spinal fluid in the great majority of cases. As evidence of this I will quote only a few writers. O'Leary and Welsh (I933) reported that in 74 cases with positive fluid in spite of much injection treatment, malaria produced complete reversal of the fluid changes in 42 per cent. and reversal of all but the Wassermann in 37 per cent. more. It may be worth while here to quote also these authors' experience of the effect of malarial treatment on the spinal fluid in cases of symptomatic neuro-syphilis as it supports the other evidence as to the powerful fundamental effect of these methods of treatment. In 249 cases of G.P.I. reversal occurred in 42 per cent. and improvement in 45 per cent. In 85 with insufficient signs to justify a diagnosis of G.P.I. but very suggestive fluid changes, complete reversal of the fluid changes occurred in half. In 65 cases of tabo-paresis complete reversal of the fluid changes occurred in 24 per cent. and reversal of all changes but the Wassermann in 7 I per cent. more. In II 6 cases of tabes complete reversal of fluid changes occurred in 43 per cent.

To revert to the effect of modern treatment in late asymptomatic neuro-syphilis, - I will quote for further evidence only from the references in Dattner's " Moderne Therapie der Neurosyphilis." Scherber in 68 cases treated with malaria saw 28 per cent. become completely negative and 6r per cent. greatly improved. Kerl reported that in 39 of 58 cases treated by malaria the fluid became completely negative, and in I8 it was greatly improved. In another series of 30 patients Kerl reported as follows. In 4 tested within a year of the 
malaria 2 had become negative and one improved; in the remaining 26 tested 3,4 and 7 years after the cure I6 had become negative, 3 almost negative, 5 improved, and 2 unchanged. Dattner in 36 cases treated with tuberculin reported complete reversal of the changes in I6 and improvement in II.

These results, which seem to be typical of general experience, seem sufficient to show that, as Kerl and many other workers have asserted strongly, we have in pyrogenetic treatment, which can very usefully be supplemented by pentavalent arsenical and by bismuth treatment, a means by which the syphilitic changes in the central nervous system can generally be arrested before symptoms of neuro-syphilis have made their appearance. It follows that G.P.I. and tabes ought to become rarities. That will come to pass when it becomes customary to test the spinal fluid in late cases of syphilis, and pyrogenetic treatment is more easily obtained than at present ; from experience of the latent period which usually elapses between recommendation of any improvement in the management of a venereal disease and its general adoption by the medical profession, I should judge that not more than ten more years will be required to bring about this one.

As regards symptomatic neuro-syphilis, for the purposes of the present discussion tabes and late meningovascular syphilis need not be dealt with in detail. Both forms usually respond well to modern treatment and, under it, are not important shorteners of life. As I shall show presently the mean age at death from tabes in males is now over $6 \mathrm{I}$.

In general paralysis of the insane everybody agrees that modern treatment, especially malarial, has made an enormous difference to the outlook. As evidence of the poor prognosis prior to the introduction of modern methods B. Dattner quotes Krafft-Ebing and Junius and Arndt who between them in 3,400 cases had never seen a case of G.P.I. that had recovered. Remissions in untreated cases appear never to have exceeded I6 per cent. in any set of statistics and they were only very rarely prolonged. Formerly the great majority of patients were dead within two years of certification and almost all within four years as is shown by Meagher's figures. In these, of 624 mental hospital cases not treated by modern 


\section{BRITISH JOURNAL OF VENEREAL DISEASES}

methods in I923, 90 per cent. were dead by the end of I927, and of 424 admitted in I924, 83 per cent. were dead three years later. In contrast with this I need quote only a few of the numerous papers that have been published to show how malaria prolongs life in G.P.I. It should be noted that most statistics probably show results in the least favourable light because for large numbers one has to rely on cases treated in mental hospitals, which deal with stages of general paresis not so favourable as the pre-certificate stage.

Surgeon-Rear-Admiral Meagher (I929) reported that of 438 cases treated in mental hospitals by malaria before the end of I924, $56 \cdot 3$ per cent. were still alive three to four years later, 24.7 per cent. having been discharged from hospital. Lt.-Col. J. A. Sinton's (I938) report on results of treatment by malaria in the mental hospitals of England and Wales during the years I927 to I936 inclusive shows that, in that time, 6,63I cases of G.P.I. were inoculated, and 3,058 , or $46 \cdot$ I per cent., were classed as having shown more or less improvement, 2I.05 per cent. having been discharged from hospital. These results are in cases which had reached the certification stage and must have included many that were in an advanced stage at the time of inoculation. In the main therefore, as already suggested, they represent perhaps the worst average which can be expected from malarial therapy of G.P.I. It has been shown well by numerous workers that the earlier the inoculation the better the result. Nicol's analysis of the results obtained at Horton Mental Hospital showed the following :-

TABLE IV.-Results of Malarial Treatment according to Duration of Symptoms Prior to Start of Treatment (Nicol).

\begin{tabular}{|c|c|c|c|c|c|c|}
\hline & \multicolumn{6}{|c|}{ Treated within } \\
\hline & $\begin{array}{c}6 \\
\text { Months. }\end{array}$ & $\begin{array}{c}12 \\
\text { Months. }\end{array}$ & $\begin{array}{c}18 \\
\text { Months. }\end{array}$ & $\begin{array}{c}24 \\
\text { Months. }\end{array}$ & Months. & $\begin{array}{l}\text { Over } 3 \\
\text { Years. }\end{array}$ \\
\hline Good remissions & 20 & II & 2 & 一 & 2 & - \\
\hline Partial , & 22 & 7 & I & 2 & - & 3 \\
\hline Still in hospital & 33 & 25 & Io & 3 & 7 & 2 \\
\hline Died in hospital & 8 & 8 & 5 & I & I & I \\
\hline
\end{tabular}

I6 


\section{VENEREAL DISEASES AND LIFE ASSURANCE}

As a further example of the value of starting treatment early may be quoted the paper by O'Leary and Welsh already mentioned in which it was reported that in 186 mental hospital cases malarial treatment was followed by complete remission in 35 per cent. and by improvement in another 35 per cent., but in 249 cases not yet certified remission occurred in 49 per cent. and improvement in another 35 per cent. Dattner reported in I29 cases treated in the Vienna Psychiatric Clinic between I922 and I924 that 8 to Io years later $38 \cdot 3$ per cent. were still in full remission, 8.6 stationary and $53 . \mathrm{I}$ per cent. dead, but of those dead not less than 25 per cent. had died of some intercurrent affection. In the 68 deceased patients in this series the duration of life after inoculation had averaged 3.8 years, which is probably at least $\mathrm{I} \cdot 8$ years more than the average in untreated cases.

The inference from the evidence already given that the well-treated syphilitic has only a minute chance of dying prematurely of late neuro-syphilis is supported by the mortality statistics contained in the reports of the Registrar-General for England and Wales, but it seems best before dealing with this evidence to discuss the outlook in syphilis of the cardio-vascular system.

You will remember that earlier in this address I quoted figures by Vonderlehr and Usilton with colleagues from the C.C.G.'s statistics which showed in patients who had been treated in the early stages of their infections with a minimum of 20 injections of an arsphenamine preparation with corresponding heavy metal and observed for Io to 20 years no case with definite cardio-vascular syphilis but 4.9 per cent. as possibly having it. In another group observed for 3 to Io years were $I \cdot 2$ per cent. with definite and $0 \cdot 2$ per cent. with possible cardiovascular syphilis. According to this one would have to reckon with 6.3 per cent. definite and possible cardiovascular syphilis in cases receiving a standard treatment which is less than is prescribed in the best clinics in this country. This percentage is made up moreover for the most part of cases of doubtful aortitis in which there is strong evidence that modern treatment has excellent effects.

To the same effect may be quoted a paper by Cole and Usilton (I936) with colleagues of the C.C.G. in which is a table illustrating the preventive effect, so far as the later 


\section{BRITISH JOURNAL OF VENEREAL DISEASES}

development of cardio-vascular syphilis is concerned, of good treatment in the early stages of syphilis. This table shows that of 323 cases treated in the early stages with more than 20 doses of arsphenamine plus heavy metal, all administered regularly, one had developed cardio-vascular syphilis during 3 to Io years as compared with $\mathrm{I} 4$ of $6 \mathrm{I} 2$ treated irregularly or with less than 20 doses. In the observation period of ro to 20 years none of Io treated regularly and adequately in the early stages; but 6 of 95 treated irregularly or with less than 20 doses had developed cardio-vascular syphilis. The authors concluded on this point that "the patient adequately and regularly treated for early syphilis and followed for from 3 to 20 years after infection will be almost exempt from cardio-vascular involvement."

As regards the prospects of prolonging life after the development of signs of aortic disease the evidence seems to be quite definite. Grant (I933) concluded from the comparison of the survival periods in 52 cases treated with neoarsphenamine and mercury with those in I20 treated only with iodide or with no anti-syphilitic remedy, all having been observed for Io years, that specific treatment after discovery of cardio-vascular syphilis definitely prolonged life. He showed also that the outlook in syphilitic cardio-vascular syphilis is by no means so gloomy as is often thought. Over one third of the cases in his series survived the Io-year observation period of the study, and the death rate of 64 per cent. in that time was no higher than in any of the other forms of heart disease in his collection of $\mathrm{I}, 000$ cases.

At a later date Padget and Moore (I935) published a report in which they compared the effect of what was described as adequate treatment after onset of symptoms with that of inadequate or no treatment. The paper was a sequel to one by Moore, Danglade and Reisinger. Besides answering certain criticisms of the earlier paper it presented the results of three years further observation of the same cases and also analysed on the same lines the results published by Grant, which have just been quoted. The results are shown in Table $\mathrm{V}$.

In this table cases which died in the first year of treatment were excluded from the comparison of adequate with inadequate treatment; this was in response to a criticism by Barnett that they did not constitute a fair I8 
TABLE V.-Outcome in Aneurysm and Syphilitic Aortic Regurgitation reported by Padget and Moore

\begin{tabular}{|c|c|c|c|c|c|c|}
\hline \multirow{3}{*}{. } & \multicolumn{2}{|c|}{ Total. } & \multirow{2}{*}{\multicolumn{2}{|c|}{$\begin{array}{c}\text { Aneurysm. } \\
\text { Patients. Dead. }\end{array}$}} & \multirow{2}{*}{\multicolumn{2}{|c|}{$\begin{array}{c}\begin{array}{c}\text { Aortic } \\
\text { Regurgitation. }\end{array} \\
\text { Patients. Dead }\end{array}$}} \\
\hline & \multirow{2}{*}{\begin{tabular}{|l} 
Patients. \\
I6I
\end{tabular}} & \multirow{2}{*}{$\frac{\text { Dead. }}{123}$} & & & & \\
\hline & & & $5^{2}$ & $4 \mathrm{I}$ & IO9 & 82 \\
\hline Died in first year of observation & 53 & 53 & I5 & I5 & 38 & 38 \\
\hline Observed for more than one year & 108 & 70 & 37 & 26 & $7 \mathrm{I}$ & 44 \\
\hline Inadequately treated & 53 & 46 & I7 & I4 & 36 & 32 \\
\hline Adequately treated. & 55 & 24 & 20 & $\mathrm{I} 2$ & 35 & 12 \\
\hline
\end{tabular}

basis. The remaining Io8 cases were divided almost evenly between the adequately and the inadequately treated. They show only 24 dead in the adequately treated to 46 in the inadequately treated, and the authors state that of the 46 deaths in inadequately treated cases 34 were due to the cardio-vascular lesions as compared with only I 7 in the 24 adequately treated. In the 70 who died the duration of life after onset of symptoms had been $4 \mathrm{I}$ months in the inadequately treated and 60 months in the adequately treated. Thus not only were there more survivals in the adequately treated group but those who had died had lived I9 months longer.

In their analysis on the same principles of the cases published in detail by Grant in this country, which have been mentioned, after discarding I 8 of the 189 cases in Grant's series because of " insufficient information" they compared the results of neoarsphenamine and mercurial treatment in $5 \mathrm{I}$ cases with those of no treatment or treatment only with iodides in 120 cases and found as follows. Of the neoarsphenamine and mercurytreated cases, 25 or 49 per cent. were dead by the end of the ro-year period and of the inadequately treated, 79 or 66 per cent. Of the survivors, 13 or 25 per cent. of the neoarsphenamine and mercury-treated cases were classed as "uneventful and unchanged " as compared with I9 or 16 per cent. of the inadequately treated. The figures agree substantially with those given in Grant's own table illustrating the comparison between those treated with neoarsphenamine and mercury, those treated only with K.I. and those not treated with any specific remedy. Grant's table showed 52 instead of 51 cases in the neoarsphenamine and mercury-treated series, 12 instead of 13 in the survivors with 


\section{BRITISH JOURNAL OF VENEREAL DISEASES}

progress "uneventful and unchanged" in the neoarsphenamine plus mercury group and 15 instead of 19 in the untreated or treated only with K.I.

Padget and Moore thus showed that their own results were in substantial agreement with those observed by Grant in demonstrating the life-prolonging effect of specific treatment after detection of cardio-vascular syphilis.

The evidence of Grant's and Padget and Moore's analyses is supported strongly by the analysis by Cole and Usilton with colleagues of the C.C.G. of the cardiovascular cases in the C.C.G.'s collection. In uncomplicated aortitis observed for not less than one year after onset, at one end of the scale were 64 cases classed as having received little arsenic and little heavy metal; of these I5 or 23.4 per cent. had died after an average of 34 months, and 49 or 76.6 per cent. were still living after an average of 53 months. In contrast with this, at the other end of the scale were I 28 cases which had been treated after detection of the cardio-vascular lesion with I3 or more arsenical and 20 or more heavy metal injections; of these, I4 or I0.9 per cent. were dead after surviving for an average of 85 months and II 4 or $89^{\cdot}$ I per cent. were alive after an average of 60 months.

In another table by these authors are shown the following. Of 102 cases marked as inadequately treated, i.e. had less than $\mathrm{I} 3$ arsenical with interim heavy metal injections, 79 or 77.4 per cent. were still alive after an average of 53 months from detection of the lesion and 23 or 22.6 per cent. were dead after an average duration of 42 months, while of 165 marked as adequately treated, I 46 or 88.5 per cent. were still alive after an average of 62 months and I9 or II. 5 per cent. were dead after an average of 77 months. In the inadequately treated cases 7.9 per cent. of the deaths were considered to be due to the vascular lesion but in the adequately treated only $2 \cdot 4$ per cent. Thus the authors concluded adequate treatment after detection of uncomplicated aortitis not only practically doubled the duration of life but lessened the frequency of cardio-vascular syphilis as a cause of death. In I9I cases of aortic regurgitation observed for a year or longer the survival period was based on the totals in living and dead. In the inadequately treated it was 40 months and in the adequately treated 55 months; 
the difference was noted as statistically significant, and the authors concluded that adequate specific treatment of aortic regurgitation definitely prolongs life.

In 59 cases of aneurysm observed for more than a year the average duration of life after detection of the lesion was 37 months under inadequate treatment but 75 months under adequate; these periods are based on figures relating to living and dead cases.

The Registrar-General's mortality statistics for England and Wales seem to afford very interesting indirect evidence of the value of modern treatment in preventing and postponing death from G.P.I. and tabes and at least in preventing cardio-vascular syphilis as represented by aneurysm.

In the last war approximately I00,000 soldiers of the British Expeditionary Force at home and abroad were treated for syphilis, and a high percentage must have

TABLE VI.-General Paralysis, Tabes Dorsalis Aneurysm and Aortic Valve Disease.

Crude Annual Death Rates per Million Living. (Also standardised mortality for certain years, in brackets.)

\begin{tabular}{|c|c|c|c|c|c|c|c|c|c|}
\hline \multirow{2}{*}{ Sex. } & \multirow{2}{*}{ Year. } & \multicolumn{2}{|c|}{$\begin{array}{l}\text { General Paralysis of } \\
\text { the Insane. }\end{array}$} & \multicolumn{2}{|c|}{ Tabes Dorsalis. } & \multicolumn{2}{|c|}{ Aneurysm. } & \multicolumn{2}{|c|}{$\begin{array}{l}\text { Aortic Valve } \\
\text { Disease. }\end{array}$} \\
\hline & & Deaths. & $\begin{array}{l}\text { Crude } \\
\text { Rates. }\end{array}$ & Deaths. & $\begin{array}{l}\text { Crude } \\
\text { Rates. }\end{array}$ & Deaths. & $\begin{array}{l}\text { Crude } \\
\text { Rates. }\end{array}$ & Deaths. & $\begin{array}{l}\text { Crude } \\
\text { Rates. }\end{array}$ \\
\hline 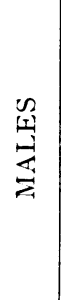 & $\begin{array}{l}1911 \\
1914 \\
1917 \\
1921 \\
1926 \\
1931 \\
1934 \\
1935 \\
1936 \\
1937\end{array}$ & $\begin{array}{r}\mathrm{I}, 763 \\
\mathrm{I}, 83 \mathrm{I} \\
\mathrm{I}, 940 \\
\mathrm{I}, 254 \\
\mathrm{I}, \mathrm{I} 6 \mathrm{I} \\
945 \\
788 \\
725 \\
652 \\
594\end{array}$ & $\begin{array}{cc}\text { IOI } & (95) \\
\text { IO2 } & (94) \\
\text { I } 26 *(96) \\
69 & (59) \\
62 & (5 \text { I) } \\
49 & (40) \\
4 \text { I } & (32) \\
37 & (28) \\
33 & (25) \\
30 & \end{array}$ & $\begin{array}{l}530 \\
600 \\
641 \\
576 \\
630 \\
557 \\
496 \\
553 \\
496 \\
473\end{array}$ & $\begin{array}{ll}30 & (29) \\
34 & (3 \mathrm{I}) \\
45 & (3 \mathrm{I}) \\
32 & (26) \\
34 & (26) \\
29 & (20) \\
26 & (17) \\
28 & (\mathrm{I} 9) \\
25 & (\mathrm{I}) \\
24 & \end{array}$ & $\begin{array}{r}935 \\
902 \\
770 \\
787 \\
777 \\
989 \\
984 \\
982 \\
\mathrm{I}, \mathrm{O} 30 \\
\mathrm{I}, \mathrm{OOI}\end{array}$ & $\begin{array}{ll}53 & (5 \mathrm{I}) \\
5 \mathrm{O} & (46) \\
5 \mathrm{I} & (37) \\
44 & (35) \\
42 & (32) \\
52 & (38) \\
5 \mathrm{I} & (36) \\
5 \mathrm{O} & (36) \\
53 & (37) \\
5 \mathrm{I} & \end{array}$ & $\begin{array}{l}\}_{\text {Avail }} \mathrm{N} \\
\text { I,9I } 7 \\
2,076 \\
2,359 \\
2, \text { I I } 8 \\
2, \text { I } 44 \\
2,051 \\
\text { I,9I9 }\end{array}$ & $\begin{array}{l}\text { ot } \\
\text { able } \\
\text { I06 } \\
\text { I I I } \\
\text { I } 23 \\
\text { I09 } \\
\text { I } 10 \\
\text { 105 } \\
97\end{array}$ \\
\hline 莣 & $\begin{array}{l}1911 \\
1914 \\
1917 \\
1921 \\
1926 \\
1931 \\
1934 \\
1935 \\
1936 \\
1937\end{array}$ & $\begin{array}{l}438 \\
434 \\
425 \\
283 \\
277 \\
259 \\
224 \\
240 \\
232 \\
253\end{array}$ & $\begin{array}{ll}23 & (2 \text { I }) \\
23 & (20) \\
22 & (\text { I } 9) \\
\text { I } 4 & \text { (I } 2) \\
\text { I } 4 & (\text { I I }) \\
\text { I } 2 & (\text { IO }) \\
\text { I I } & (8) \\
\text { I I } & (9) \\
\text { I I } & (8) \\
\text { I } 2 & \end{array}$ & $\begin{array}{l}105 \\
120 \\
\text { I } 6 \\
\text { I } 6 \\
\text { I } 17 \\
\text { I } 14 \\
107 \\
118 \\
104 \\
1116\end{array}$ & $\begin{array}{ll}6 & (5) \\
6 & (5) \\
6 & (5) \\
6 & (5) \\
6 & (4) \\
5 & (4) \\
5 & (3) \\
6 & (4) \\
5 & (3) \\
5 & \end{array}$ & $\begin{array}{l}225 \\
229 \\
225 \\
205 \\
245 \\
325 \\
431 \\
459 \\
490 \\
528\end{array}$ & $\begin{array}{ll}\text { I2 } & \text { (I I ) } \\
\text { I2 } & \text { (IO) } \\
\text { I I } & \text { (IO) } \\
\text { I0 } & (8) \\
\text { I2 } & (9) \\
\text { I6 } & \text { (10) } \\
20 & (\text { I } 3) \\
22 & (\text { I } 4) \\
23 & (\text { I } 6) \\
25 & \end{array}$ & $\left\{\begin{array}{r}\text { No } \\
\text { Avai } \\
850 \\
956 \\
\text { I, I67 } \\
\text { I,044 } \\
\text { I,048 } \\
\text { I, O I 4 } \\
969\end{array}\right.$ & $\begin{array}{r}t \\
\text { able } \\
43 \\
47 \\
56 \\
50 \\
50 \\
48 \\
45\end{array}$ \\
\hline
\end{tabular}

* Based on civilian deaths and civilian population. 


\section{BRITISH JOURNAL OF VENEREAL DISEASES}

survived the war. It is reasonable to believe that these I00,000 are evidence of a great increase in the incidence of syphilis in the population, both male and female, of this country, and some observers have voiced an expectation that by now we should be reaping the harvest of it in the form of an increased mortality from such late effects as G.P.I., tabes and cardio-vascular syphilis. That expectation is being substantiated in aneurysm but not in G.P.I. and tabes as is shown in Table VI showing the deaths and crude rates per million of the population from these three late effects of syphilis, as well as those from aortic valve disease, which I will discuss separately.

Table VI shows that in G.P.I. the crude death rate per million fell in males from 69 in I92I to 30 in I937 and in females during the same period from I4 to 12 . In tabes in the same period it fell in males from 32 to 24 and in females from 6 to 5 ; in aneurysm it rose in males from 44 to $5 \mathrm{I}$ and in females from Io to 25 .

The connection between aortic valve disease and syphilis is admittedly by no means so close as is that of the other three diseases mentioned, but in view of the possibility that a great increase in cardio-vascular syphilis might be reflected in death rates from aortic regurgitation I have included them in Table VI as well as in Table X, which shows mean ages at death. As you will see, these - rates do not reveal any significant evidence of the influence of changes in the incidence of cardio-vascular syphilis. Accordingly, beyond mentioning that the mean age at death rose in this disease as in G.P.I. and tabes, I will not discuss this disability further.

The figures relating to G.P.I., tabes and aneurysm seem to be strong evidence of intervening factors which are operating to prevent our reaping fully the expected harvest of an increased incidence of late effects of syphilis as a result of conditions in the last war. The factors in question are operating more powerfully in males than in females and in G.P.I. and tabes than in aneurysm. Two which seem to be most probable are treatment in the early stages and treatment after development of late manifestations.

As to the preventive effect of treatment in the early stages, it does not seem possible otherwise to explain how the crude death rate from aneurysm in females has increased two and a half times (standardised rate $\mathrm{I} \frac{1}{2}$ times) 
while that in males has increased by less than one seventh (standardised rate by less than one seventeenth) because it is unbelievable that the increases in incidence of infection of the two sexes during the last war were in those proportions. On the other hand, we know that probably most of the men, being in the Services, received treatment in the early stages of their infection, while probably most of the women were untreated; the latter was because the National V.D. Scheme was only in its infancy. It is true that one might invoke the factor of prompter detection and treatment of the aortic lesion in men than in women, but it seems very difficult to believe that this could have played more than a very minor part in the very marked difference between the increases in these death rates.

If we can accept the explanation that treatment in the earliest stages of the infection has been the dominating factor in preventing the death rate from aneurysm in men from rising so greatly as in women, we can admit also that it must have played some part in converting an expected rise in deaths from G.P.I. and tabes into an actual fall, though admittedly another factor, pyrogenetic and other treatment of value in parenchymatous neuro-syphilis, has also been at work here.

The inevitable conclusion is that even so little treatment as was customary in the Services during the last war, namely 7 to Io injections of an arsphenamine preparation concurrently with as many of mercury, has prevented a great amount of late cardio-vascular and neuro-syphilis.

The conclusion is interesting in view of the gloomy forebodings as to the future of syphilitic soldiers treated by so-called war courses, which were expressed by observers, both British and foreign, during the last war. It is also important because not only does it support the evidence of other workers that inadequate treatment does not, as is often stated, promote an increased incidence of late effects but it shows that, even if inadequate, treatment in the early stages prevents them probably to a degree which is proportional to its approach to the standard classed as adequate.

The falls in the rates of death from G.P.I. and tabes are doubtless due largely to the effects of pyrogenetic and other special treatment which has been found 


\section{BRITISH JOURNAL OF VENEREAL DISEASES}

valuable for parenchymatous neuro-syphilis. They are more apparent in G.P.I. than in tabes and in men than in women because these special forms of treatment have been applied more and are known to be more effective in G.P.I. than in tabes; also it seems probable that they are applied more quickly after the onset of signs in males than in females.

TABLE VII.-General Paralysis of the Insane. Death Rates, per Million of the Population in Different Age Groups.

\begin{tabular}{|c|c|c|c|c|c|c|c|c|c|c|c|c|c|}
\hline \multirow{3}{*}{$\begin{array}{l}x \\
\text { 工nd } \\
\text { s. }\end{array}$} & \multirow{3}{*}{ Year. } & \multicolumn{12}{|c|}{ Age Groups. } \\
\hline & & \multicolumn{2}{|c|}{$25-$} & \multicolumn{2}{|c|}{$35 \div$} & \multicolumn{2}{|c|}{$45-$} & \multicolumn{2}{|c|}{$55-$} & \multicolumn{2}{|c|}{$65-$} & \multicolumn{2}{|c|}{$75-$} \\
\hline & & No. & Rate. & No. & Rate. & No. & Rate. & No. & Rate. & No. & Rate. & No. & Rate. \\
\hline 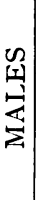 & $\begin{array}{l}\text { I92 I } \\
1926 \\
\text { I931 } \\
1934 \\
1935 \\
1936 \\
1937\end{array}$ & $\begin{array}{r}\text { I I } 3 \\
8 \text { I } \\
65 \\
33 \\
29 \\
30 \\
21\end{array}$ & $\begin{array}{r}43 \cdot 0 \\
30 \cdot 5 \\
21 \cdot 4 \\
10 \cdot 0 \\
8 \cdot 7 \\
9 \cdot 0 \\
6 \cdot 3\end{array}$ & $\begin{array}{l}497 \\
387 \\
287 \\
232 \\
174 \\
149 \\
137\end{array}$ & $\begin{array}{r}\text { I } 99 \cdot 3 \\
\text { I } 58 \cdot 3 \\
\text { I I } 5 \cdot 7 \\
89 \cdot 9 \\
66 \cdot 1 \\
55 \cdot 2 \\
49 \cdot 4\end{array}$ & $\begin{array}{l}382 \\
404 \\
332 \\
265 \\
265 \\
252 \\
213\end{array}$ & $\begin{array}{r}\text { I } 76 \cdot 5 \\
\text { I } 78 \cdot 8 \\
\text { I } 45 \cdot 8 \\
\text { I I } 4.9 \\
\text { I I } 4.5 \\
\text { I } 08 \cdot 2 \\
9 \text { I } \cdot 0\end{array}$ & $\begin{array}{l}190 \\
205 \\
201 \\
203 \\
187 \\
162 \\
165\end{array}$ & \begin{tabular}{|r} 
I 33.9 \\
I 29.5 \\
I I I.5 \\
IO 8.9 \\
98.9 \\
84.4 \\
85.1
\end{tabular} & $\begin{array}{l}52 \\
57 \\
44 \\
39 \\
50 \\
40 \\
41\end{array}$ & $\begin{array}{l}69 \cdot 6 \\
68 \cdot 9 \\
47 \cdot 5 \\
37 \cdot 7 \\
47 \cdot 0 \\
36 \cdot 6 \\
36 \cdot 6\end{array}$ & $\begin{array}{r}6 \\
15 \\
5 \\
1 \\
4 \\
2 \\
4\end{array}$ & $\begin{array}{r}23.7 \\
54.0 \\
15.8 \\
2.8 \\
\text { I I.0 } \\
5.4 \\
10.5\end{array}$ \\
\hline 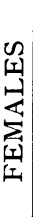 & $\begin{array}{l}1921 \\
1926 \\
1931 \\
1934 \\
1935 \\
1936 \\
1937\end{array}$ & $\begin{array}{l}36 \\
21 \\
23 \\
\text { I } 4 \\
\text { I } 5 \\
\text { I } 2 \\
\text { I } 4\end{array}$ & $\begin{array}{r}\text { I I.4 } \\
6 \cdot 5 \\
6 \cdot 9 \\
4 \cdot 1 \\
4 \cdot 4 \\
3 \cdot 4 \\
4 \cdot 0\end{array}$ & $\begin{array}{l}83 \\
87 \\
66 \\
62 \\
79 \\
58 \\
68\end{array}$ & $\begin{array}{l}29 \cdot 0 \\
29 \cdot 9 \\
22 \cdot 1 \\
20 \cdot 4 \\
25 \cdot 7 \\
18 \cdot 6 \\
21 \cdot 6\end{array}$ & $\begin{array}{r}92 \\
105 \\
97 \\
77 \\
80 \\
91 \\
78\end{array}$ & $\begin{array}{l}39 \cdot 5 \\
4 I \cdot 8 \\
36 \cdot 5 \\
28 \cdot 6 \\
29 \cdot 5 \\
33 \cdot 2 \\
28 \cdot 3\end{array}$ & $\begin{array}{l}42 \\
45 \\
41 \\
50 \\
48 \\
51 \\
70\end{array}$ & $\begin{array}{l}26 \cdot 7 \\
25 \cdot 8 \\
20 \cdot 4 \\
23 \cdot 7 \\
22 \cdot 2 \\
23 \cdot 1 \\
31 \cdot 2\end{array}$ & $\begin{array}{r}20 \\
10 \\
17 \\
9 \\
7 \\
10 \\
19\end{array}$ & $\begin{array}{r}2 \mathrm{I} \cdot 5 \\
9 \cdot 9 \\
\mathrm{I} 5 \cdot \mathrm{I} \\
7 \cdot \mathrm{I} \\
5 \cdot 4 \\
7 \cdot 5 \\
\mathrm{I} 3 \cdot 9\end{array}$ & $\begin{array}{l}7 \\
2 \\
\text { I } \\
\text { I } \\
\text { I } \\
2 \\
0\end{array}$ & $\begin{array}{l}\text { I } 7 \cdot 4 \\
4 \cdot 5 \\
2 \cdot 1 \\
I \cdot 8 \\
I \cdot 8 \\
3 \cdot 4 \\
0\end{array}$ \\
\hline
\end{tabular}

When the changes in the death rates in the different age groups are considered it is seen that in G.P.I. (Table VII and Fig. I) the steepest falls were in the age periods under 55 ; whereas in I92I the rates in males in the two tenyear age periods between 35 and 55 were respectively 60 and 40 more than in the period 55 to 65 , in I937 the rate was more than 35 less in the age period 35 to 45 and only 6 more in the period 45 to 55 .

In tabes, as Table VIII and Fig. I show, the rates were highest in the age periods 55 to 65 and 65 to 75 , and the falls in males were most pronounced in the periods under 65 . 
VENEREAL DISEASES AND LIFE ASSURANCE

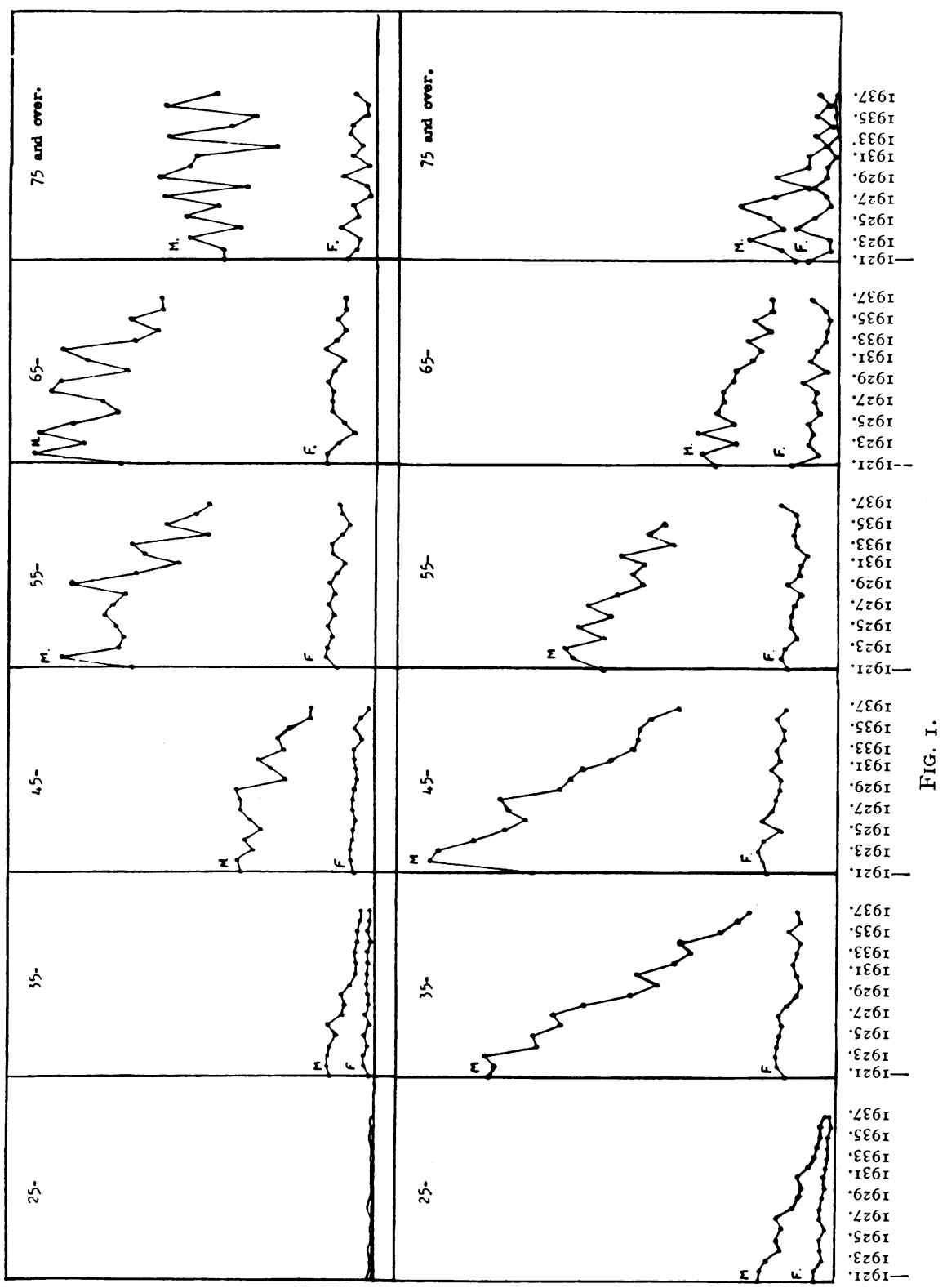

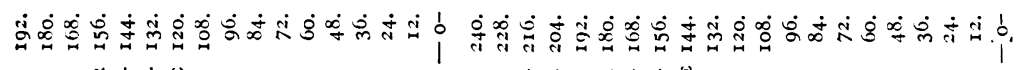
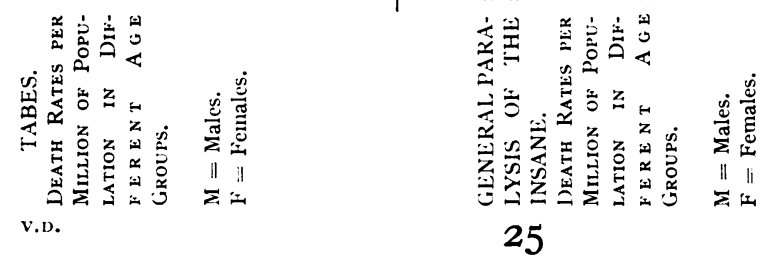
BRITISH JOURNAL OF VENEREAL DISEASES

TABle VIII.-Tabes. Death Rates, per Million of the Population, in Different Age Groups.

\begin{tabular}{|c|c|c|c|c|c|c|c|c|c|c|c|c|c|}
\hline \multirow{3}{*}{ Sex. } & \multirow{3}{*}{ Year. } & \multicolumn{12}{|c|}{ Age Group. } \\
\hline & & \multicolumn{2}{|c|}{$25-$} & \multicolumn{2}{|c|}{$35-$} & \multicolumn{2}{|c|}{$45-$} & \multicolumn{2}{|c|}{$55-$} & \multicolumn{2}{|c|}{$65-$} & \multicolumn{2}{|c|}{$75-$} \\
\hline & & No. & Rate. & No. & Rate. & No. & Rate. & No. & Rate. & No. & Rate. & No. & Rate. \\
\hline \multirow{7}{*}{ 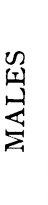 } & I92I & I 4 & $5 \cdot 3$ & 65 & $26 \cdot I$ & I 67 & $77 \cdot 2$ & I99 & $140 \cdot 2$ & I09 & I $45^{\circ} 9$ & 22 & $86 \cdot 9$ \\
\hline & I926 & 6 & $2 \cdot 3$ & 67 & $27 \cdot 4$ & 162 & $7 \mathrm{I} \cdot 7$ & 244 & I $54 \cdot I$ & 122 & I $47 \cdot 5$ & 25 & $90 \cdot 0$ \\
\hline & 1931 & 3 & $x \cdot O$ & 29 & $\mathrm{II} \cdot 7$ & I 36 & $59 \cdot 7$ & 202 & I I I 17 & I 53 & $165 \cdot I$ & 33 & $104 \cdot 3$ \\
\hline & 1934 & I & 0.3 & 28 & $10 \cdot 8$ & I 30 & $56 \cdot 4$ & I 79 & $96 \cdot I$ & 129 & $\mathrm{I} 24^{\circ} 8$ & 29 & $82 \cdot 7$ \\
\hline & I935 & 9 & $2 \cdot 7$ & 29 & II $\cdot O$ & II 3 & $4^{8 \cdot 8}$ & 227 & I $20 \cdot 0$ & I 49 & $140 \cdot 0$ & 25 & $68 \cdot 8$ \\
\hline & 1936 & 3 & 0.9 & 26 & $9 \cdot 6$ & 88 & $37 \cdot 8$ & 200 & $104 \cdot 2$ & I 33 & I $2 \mathrm{I} \cdot 7$ & 45 & $\mathrm{I} 2 \mathrm{I} \cdot \mathrm{I}$ \\
\hline & 1937 & 4 & $I \cdot 2$ & 26 & $9 \cdot 4$ & 87 & $37^{\circ} \cdot 2$ & 183 & 94.4 & I 37 & I $22 \cdot 3$ & 35 & $92 \cdot 0$ \\
\hline \multirow{7}{*}{ 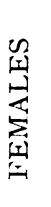 } & I92I & 5 . & $I \cdot 6$ & 8 & $2 \cdot 8$ & 32 & 13.7 & 36 & $22 \cdot 9$ & 27 & $29 \cdot I$ & 7 & $\mathrm{I} 7 \cdot 4$ \\
\hline & 1926 & 2 & $0 \cdot 6$ & Io & $3 \cdot 4$ & $3 \mathrm{I}$ & I $2 \cdot 3$ & 42 & $24^{\circ} 0$ & 26 & $25 \cdot 7$ & 6 & 13.6 \\
\hline & I93I & 2 & 0.6 & I6 & $5 \cdot 4$ & $3 \mathrm{I}$ & I I $\cdot 6$ & 37 & $18 \cdot 4$ & $2 \mathrm{I}$ & $18 \cdot 6$ & 7 & 14.4 \\
\hline & I934 & 3 & $0 \cdot 9$ & 6 & $2 \cdot 0$ & 23 & $8 \cdot 5$ & 43 & $20 \cdot 4$ & 23 & $I 8 \cdot I$ & 8 & $14 \cdot 5$ \\
\hline & I935 & 2 & 0.6 & I 5 & $4 \cdot 9$ & 35 & $12 \cdot 9$ & 33 & $15 \cdot 3$ & 30 & 23.0 & 3 & $5 \cdot 2$ \\
\hline & 1936 & o & o & I I & $3 \cdot 5$ & 26 & $9 \cdot 5$ & $4 \mathrm{I}$ & $18 \cdot 6$ & 23 & $17 \cdot 2$ & 3 & $5 \cdot x$ \\
\hline & 1937 & I & $0 \cdot 3$ & 9 & $2 \cdot 9$ & 24 & $8 \cdot 7$ & 47 & $20 \cdot 9$ & 25 & $18 \cdot 2$ & 8 & $13 \cdot 3$ \\
\hline
\end{tabular}

In aneurysm, as in tabes, the rates were generally higher after 55, and it is clear from Table IX and Fig. 2 that in males the rise in the gross rate shown in Table VI

TABLE IX.-Aneurysm. Death Rates, per Million of the Population, in the Different Age Groups.

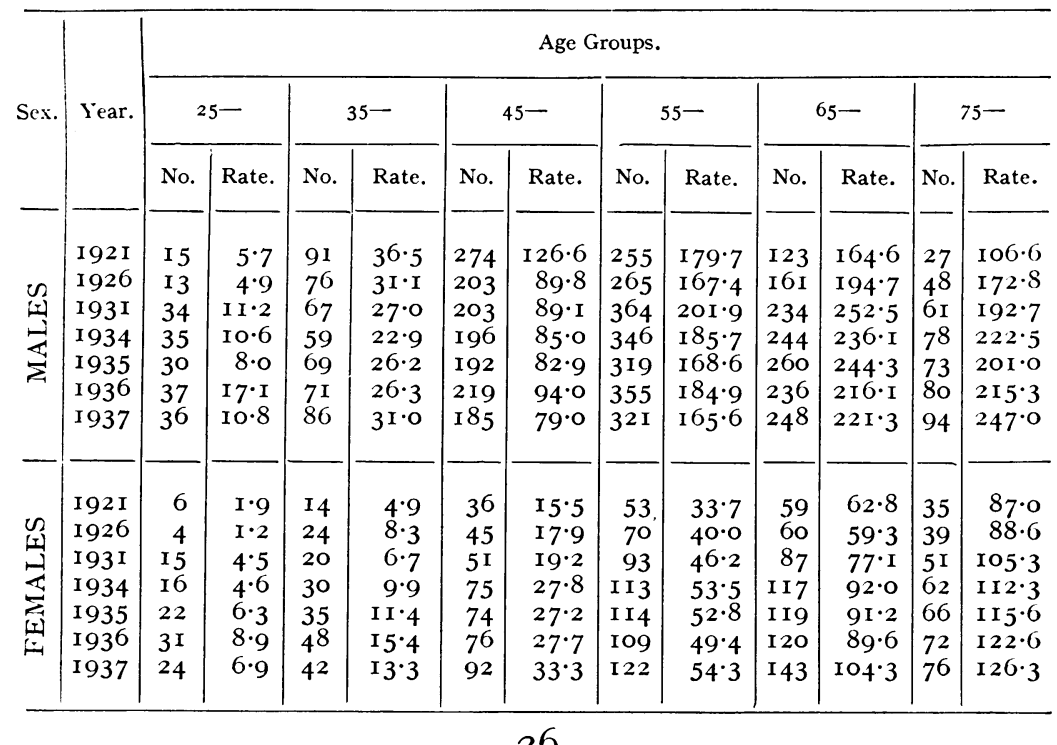


VENEREAL DISEASES AND LIFE ASSURANCE

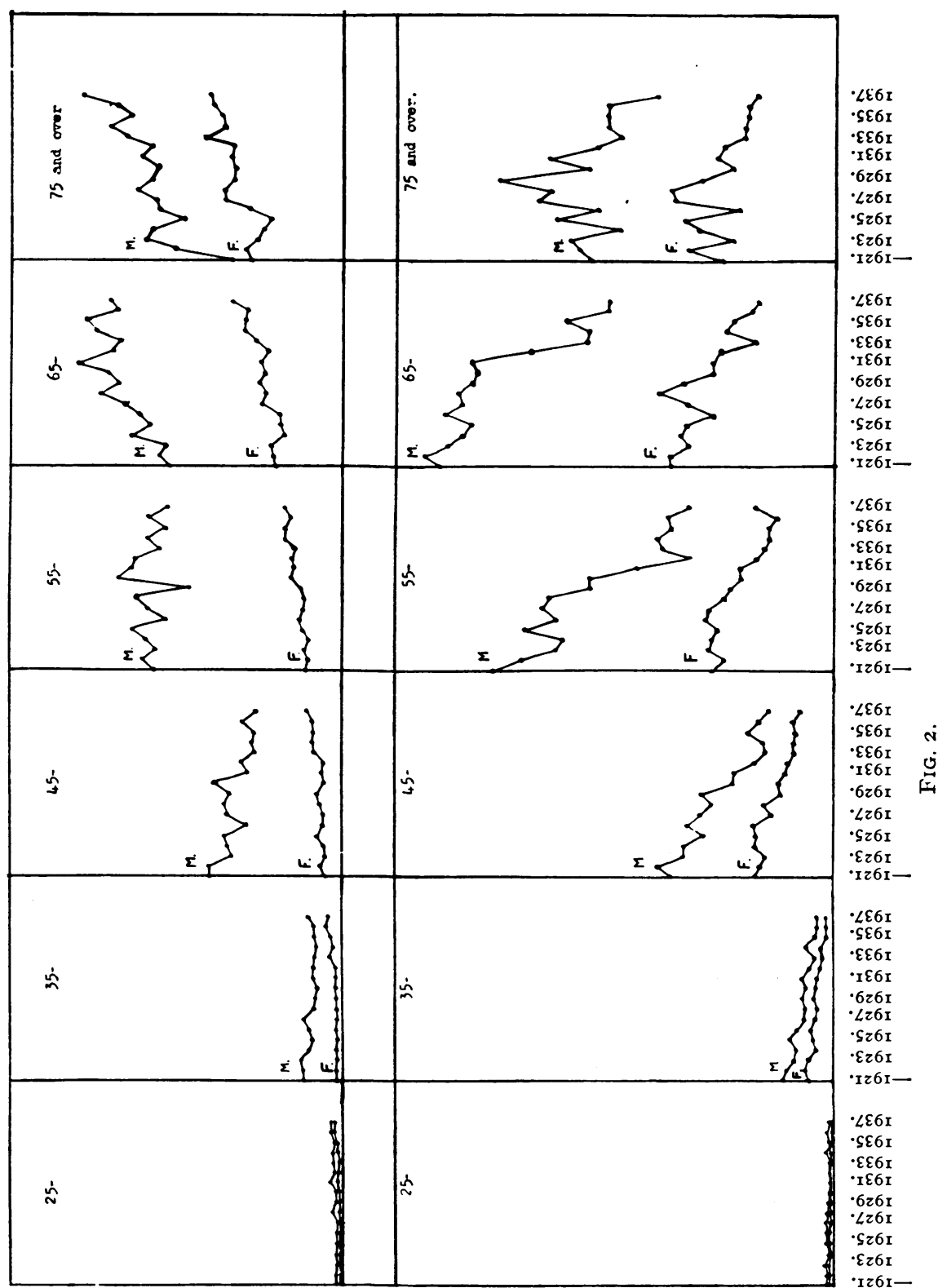

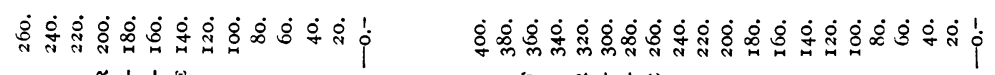

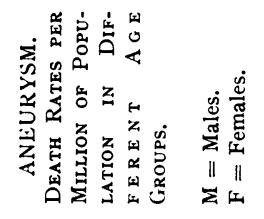

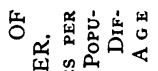

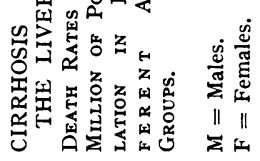




\section{BRITISH JOURNAL OF VENEREAL DISEASES}

is attributable to a rise in the rates after the age of 65 . In females, on the other hand, rises in incidence occurred in all the age periods.

These changes are reflected in the mean ages at death which, as shown in Table $\mathrm{X}$, have risen in all diseases except aneurysm in females.

TABle X.-Mean Ages at Death (Over Twenty Years of Age) from G.P.I., Tabes, Aneurysm, Aortic Valve Disease and Cirrhosis of Liver.

\begin{tabular}{|c|c|c|c|c|c|c|c|c|c|c|}
\hline \multirow{2}{*}{ Year. } & \multicolumn{2}{|c|}{ G.P.I. } & \multicolumn{2}{|c|}{ Tabes. } & \multicolumn{2}{|c|}{ Aneurysm. } & \multicolumn{2}{|c|}{$\begin{array}{c}\text { Aortic Valve } \\
\text { Disease. }\end{array}$} & \multicolumn{2}{|c|}{$\begin{array}{l}\text { Cirrhosis of } \\
\text { Liver. }\end{array}$} \\
\hline & M. & F. & M. & F. & M. & F. & M. & F. & M. & F. \\
\hline 1921 & $46 \cdot 5$ & $47 \cdot 8$ & $56 \cdot 5$ & $57 \cdot 8$ & $55 \cdot 7$ & $62 \cdot 2$ & . & & $5^{8 \cdot 3}$ & $58 \cdot 0$ \\
\hline 1922 & $47 \cdot 2$ & $46 \cdot 6$ & 57.8 & $56 \cdot 6$ & $57 \cdot 4$ & $6 x \cdot 7$ & & & $58 \cdot 4$ & $5^{8 \cdot 2}$ \\
\hline 1923 & $47 \cdot 5$ & $47 \cdot 3$ & $57 \cdot 8$ & $56 \cdot 2$ & $57 \cdot 0$ & $6 x \cdot 5$ & $60 \cdot 5$ & $65 \cdot 2$ & $58 \cdot 8$ & $58 \cdot 0$ \\
\hline 1924 & 47.8 & $47 \cdot 6$ & $57 \cdot 8$ & $55 \cdot 9$ & $57 \cdot 6$ & $6 I \cdot 6$ & & & $5^{8 \cdot 9}$ & $59 \cdot 0$ \\
\hline 1925 & $47 \cdot 7$ & $47 \cdot 6$ & $58 \cdot 5$ & 55.8 & $57 \cdot 9$ & $59 \cdot 7$ ! & & & $59^{\circ} 0$ & $58 \cdot 4$ \\
\hline 1926 & & & & & & & & & & \\
\hline to & $48 \cdot 8$ & $47 \cdot 7$ & $5^{8 \cdot 9}$ & $57 \cdot 3$ & - & - & - & - & - & - \\
\hline 1932 & & & & & & & & & & \\
\hline 1933 & $49 \cdot 2$ & $47 \cdot 7$ & $60 \cdot 3$ & $57 \cdot 8$ & $59 \cdot 0$ & $60 \cdot 6$ & & & $\begin{array}{l}61 \cdot 3 \\
60 \cdot 8\end{array}$ & $58 \cdot 0$ \\
\hline 1934 & $\begin{array}{l}49 \cdot 5 \\
49 \cdot 7\end{array}$ & $\begin{array}{l}47 \cdot 9 \\
47 \cdot 6\end{array}$ & $59 \cdot 9$ & $59 \cdot 3$ & $59 \cdot 4$ & $\begin{array}{l}60 \cdot 9 \\
50 \cdot 6\end{array}$ & $6 \mathrm{I} \cdot 2$ & $66 \cdot 9$ & $\begin{array}{l}000 \\
61 \cdot 3\end{array}$ & $\begin{array}{l}590 \\
61 \cdot 0\end{array}$ \\
\hline $\begin{array}{l}1935 \\
1936\end{array}$ & $\begin{array}{l}49 \cdot 7 \\
50 \cdot 5\end{array}$ & $\begin{array}{l}47 \cdot 6 \\
49 \cdot 0\end{array}$ & $\begin{array}{l}60 \cdot 0 \\
6 r \cdot 4\end{array}$ & $\begin{array}{l}56 \cdot 9 \\
58 \cdot 2\end{array}$ & $\begin{array}{l}59 \cdot 0 \\
58.8\end{array}$ & $\begin{array}{l}59 \cdot 6 \\
58 \cdot 5\end{array}$ & $6 I \cdot 3$ & 66.9 & $\begin{array}{l}01 \cdot 3 \\
6 I \cdot 6\end{array}$ & $60 \cdot 6$ \\
\hline $\begin{array}{l}193^{\circ} \\
1937\end{array}$ & $\begin{array}{l}50 \cdot 5 \\
51 \cdot 0\end{array}$ & $\begin{array}{l}49 \cdot 0 \\
50 \cdot 3\end{array}$ & $6 I \cdot I$ & $59 \cdot 8$ & 59.5 & 59.3 & & & $6 I \cdot 3$ & $60 \cdot 2$ \\
\hline
\end{tabular}

\section{Differences}

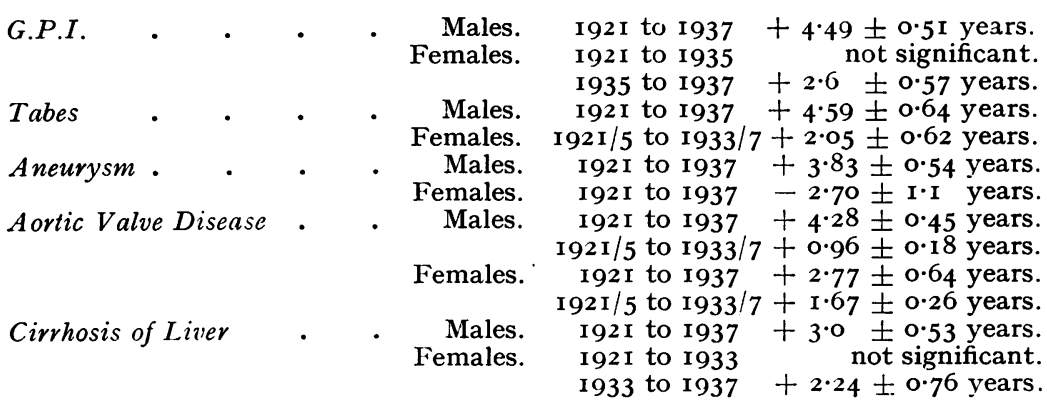

In G.P.I. from I92I to I930 the mean age at death rose in males from $46 \cdot 52$ to $48 \cdot 65$, or $2 \cdot 13 \pm 0 \cdot 44$ years; from I 930 to I937 it rose from $48 \cdot 65$ to $5 \mathrm{I} \cdot 0 \mathrm{I}$, or $2 \cdot 36 \pm 0.53$ years, and altogether from I92I to I937 the total rise was $4.49 \pm 0.5 \mathrm{I}$ years. In females, on the other hand, there was no significant change in the mean ages at death from I92I to I935, the figures ranging from 46.6 in 1922 to 
47.9 in I934; from I935 to I937, however, there was a rise of $2.63 \pm 0.57$ years, namely from $47 \cdot 67$ to $50 \cdot 3$.

In tabes from I92I to I930 the mean age at death in males rose from 56.53 to $59 \cdot 47$, or $2 \cdot 93 \pm 0.596$ years ; from 1930 to 1937 there was a further rise of $\mathrm{I} \cdot 65 \pm 0.6 \mathrm{I}$ years, and altogether from I92I to I937 there was a rise of $4.59 \pm 0.64$ years to $6 \mathrm{I} \cdot \mathrm{I} 2$. In females, on the other hand, the mean ages at death fluctuated more, and the differences between individual years were not significant, having regard to the numbers of deaths, but in the five years I933 to I937 the mean age at death was $2 \cdot 05 \pm 0 \cdot 62$ years higher at $58 \cdot 48$ than in the five years I92I to I925.

In aneurysm the mean age at death in males rose from 55.74 in I92I to 57.99 in 1925 , that is $2.55 \pm 0.352$ years. From I925 to I933 the rise was I.04 years, and from I 933 to 1937 it was not significant. The total rise in the mean age at death in males from I92I to I937 was $3.83 \pm 0.54$ years. In females on the contrary the mean age at death declined from $62 \cdot 2$ in I92I to 59.3 in 1937 , that is 2.705 \pm I.II years.

It would take us too far from our purpose if we discussed the reasons for these changes in the mean ages at death, but whatever their cause the important fact for us here is that death from the late effects of syphilis under discussion, and from aortic valve disease which is often a late effect, occurred in 1937 at the following mean ages.

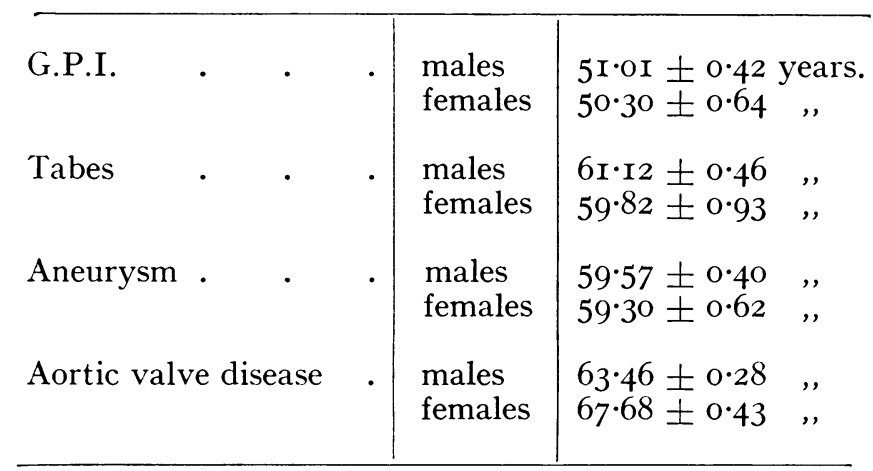

Before attempting to sum up the conclusions which may be drawn from the evidence I have given you, I must refer to the figures relating to cirrhosis of the liver which are shown in Table XI. At your discussion on the 


\section{BRITISH JOURNAL OF VENEREAL DISEASES}

prognosis of syphilis which was held in 1927 your President enquired if we might expect some increase in deaths

TABLE XI.-Cirrhosis of Liver. Death Rates, per Million of the Population, in Different Age Groups.

\begin{tabular}{|c|c|c|c|c|c|c|c|c|c|c|c|c|c|}
\hline \multirow{3}{*}{ 䓌 } & \multirow{3}{*}{ Year. } & \multicolumn{12}{|c|}{ Age Groups. } \\
\hline & & \multicolumn{2}{|c|}{$25-$} & \multicolumn{2}{|c|}{$35-$} & \multicolumn{2}{|c|}{$45-$} & \multicolumn{2}{|c|}{$55-$} & \multicolumn{2}{|c|}{$65-$} & \multicolumn{2}{|r|}{$75-$} \\
\hline & & No. & Rate. & No. & Rate. & No. & Rate. & No. & Rate. & No. & Rate. & No. & Rate. \\
\hline $\begin{array}{l}\text { 号 } \\
\text { 岁 } \\
\text { 岁 }\end{array}$ & $\begin{array}{l}1921 \\
1926 \\
1931 \\
1934 \\
1935 \\
1936 \\
1937\end{array}$ & $\begin{array}{r}17 \\
17 \\
7 \\
8 \\
\text { 10 } \\
17 \\
9\end{array}$ & $\begin{array}{l}6 \cdot 5 \\
6 \cdot 4 \\
2 \cdot 3 \\
2 \cdot 4 \\
3 \cdot 0 \\
5 \cdot 1 \\
2 \cdot 7\end{array}$ & $\begin{array}{r}\text { I } 7 \\
81 \\
72 \\
70 \\
46 \\
44 \\
46\end{array}$ & $\begin{array}{l}46 \cdot 9 \\
33 \cdot 1 \\
29 \cdot 0 \\
27 \cdot 1 \\
17 \cdot 5 \\
16 \cdot 3 \\
16 \cdot 6\end{array}$ & $\begin{array}{l}337 \\
3 \mathrm{I} 4 \\
2 \mathrm{I} 8 \\
\mathrm{I} 57 \\
\mathrm{I} 88 \\
\mathrm{I} 66 \\
\mathrm{I} 43\end{array}$ & $\begin{array}{r}\text { I } 55 \cdot 8 \\
\text { I } 39 \cdot 0 \\
95 \cdot 4 \\
68 \cdot 1 \\
8 I \cdot 2 \\
7 I \cdot 3 \\
6 I \cdot I\end{array}$ & $\begin{array}{l}464 \\
420 \\
339 \\
3 \mathrm{I} 2 \\
292 \\
302 \\
268\end{array}$ & $\begin{array}{l}327 \cdot 0 \\
265 \cdot 3 \\
\text { I } 88 \cdot 2 \\
\text { I } 67 \cdot 4 \\
\text { I } 54 \cdot 4 \\
\text { I } 57 \cdot 3 \\
\text { I } 38 \cdot 3\end{array}$ & $\begin{array}{l}283 \\
308 \\
322 \\
243 \\
275 \\
238 \\
243\end{array}$ & $\begin{array}{l}378 \cdot 8 \\
372 \cdot 2 \\
347 \cdot 4 \\
235 \cdot 1 \\
258 \cdot 4 \\
217 \cdot 7 \\
216 \cdot 8\end{array}$ & $\begin{array}{l}59 \\
63 \\
86 \\
76 \\
79 \\
81 \\
64\end{array}$ & $\begin{array}{l}233 \cdot 0 \\
226 \cdot 9 \\
271 \cdot 7 \\
216 \cdot 8 \\
217 \cdot 6 \\
218 \cdot 0 \\
168 \cdot 2\end{array}$ \\
\hline 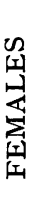 & $\begin{array}{l}1921 \\
1926 \\
1931 \\
1934 \\
1935 \\
1936 \\
1937\end{array}$ & $\begin{array}{r}\text { I6 } \\
\text { I6 } \\
\text { I I } \\
20 \\
4 \\
4 \\
\text { II }\end{array}$ & $\begin{array}{l}5 \cdot I \\
4 \cdot 9 \\
3 \cdot 3 \\
5 \cdot 8 \\
I \cdot I \\
I \cdot I \\
3 \cdot 2\end{array}$ & $\begin{array}{l}65 \\
60 \\
47 \\
35 \\
19 \\
23 \\
23\end{array}$ & $\begin{array}{r}22 \cdot 7 \\
20 \cdot 7 \\
15 \cdot 7 \\
\mathrm{II} \cdot 5 \\
6 \cdot 2 \\
7 \cdot 4 \\
7 \cdot 3\end{array}$ & $\begin{array}{r}\text { I } 73 \\
\text { 19I } \\
\text { I23 } \\
103 \\
99 \\
104 \\
85\end{array}$ & $\begin{array}{l}74 \cdot 3 \\
76 \cdot 0 \\
46 \cdot 2 \\
38 \cdot 2 \\
36 \cdot 5 \\
37 \cdot 9 \\
30 \cdot 8\end{array}$ & $\begin{array}{l}182 \\
213 \\
182 \\
130 \\
\text { I33 } \\
\text { I1 } 7 \\
\text { I66 }\end{array}$ & $\begin{array}{r}\text { I I } 6 \cdot \mathrm{I} \\
\text { I } 2 \mathrm{I} \cdot 8 \\
90 \cdot 4 \\
6 \mathrm{I} \cdot 6 \\
6 \mathrm{I} \cdot 6 \\
53 \cdot \mathrm{I} \\
73 \cdot 9\end{array}$ & $\begin{array}{r}\text { I } 44 \\
\text { I } 6 \\
\text { I } 29 \\
\text { r } 30 \\
\text { I } 24 \\
105 \\
99\end{array}$ & $\begin{array}{r}\text { I } 54 \cdot 4 \\
\text { I I } 4 \cdot 7 \\
\text { I I } 4.3 \\
\text { IO2.3 } \\
95 \cdot 0 \\
78 \cdot 4 \\
72 \cdot 2\end{array}$ & $\begin{array}{l}43 \\
40 \\
54 \\
47 \\
47 \\
48 \\
43\end{array}$ & $\begin{array}{r}\text { 106.9 } \\
90 \cdot 9 \\
\text { I II.4 } \\
85 \cdot 2 \\
82 \cdot 3 \\
81 \cdot 7 \\
7 \mathrm{I} \cdot 5\end{array}$ \\
\hline
\end{tabular}

from late effects of all the treatment now recommended. Assuming that treatment is conducted under a careful watch for toxic effects on the kidneys, the only late effect of treatment which I can think of is cirrhosis of the liver. Quite possibly some cirrhosis of the liver has occurred but there is no evidence of it in the death rates.

I come now to the inferences from the evidence I have provided. What effect has a syphilitic infection on the prospects of a proposer for life assurance surviving the normal period on which presumably premiums are calculated?

Admittedly this is very controversial ground, and I submit the following mainly as a stimulant of discussion.

I suggest that the answer cannot be found in tables which state ratios of actual to expected deaths in syphilitics because treatment makes a very great difference to the prospects of survival, as I have tried to show.

It seems most convenient to deal with this problem by considering examples, and I propose that they shall be males. 
(I) The proposer contracted syphilis four or more years ago, was treated from the sero-negative primary stage on lines regarded as thorough by good syphilologists in this country, his blood has remained negative from the beginning and his spinal fluid was found negative two years after completion of treatment. I suggest that the chances of this man developing a life-shortening effect of syphilis are negligible. I would give the same opinion if his spinal fluid had not been examined, because I have never seen a case of this kind with positive fluid.

(2) The proposer contracted syphilis four or more years ago. Treatment was started in the secondary stage, was thorough as in the first case, was continued for three courses after the serum reactions became negative and blood and spinal fluid were negative two years after suspension of treatment.

In this case, the fact of the spinal fluid being negative two years after suspension of treatment practically rules out any prospect of the proposer developing neurosyphilis in later life, and the only danger seems to be in the cardio-vascular system. Here if we accept for guidance the figures of Vonderlehr and Usilton, although they probably put the results in their own cases in a worse light than if all their cases which received standard treatment could have been followed up, and although the present indications are that patients treated on the lines now usual in British practice will probably fare better than those in the C.C.G.'s series, it seems reasonable to expect that not more than $I$ in 60 would develop any dangerous form of cardio-vascular lesion, and a fairly high proportion of people who insure there lives for any considerable amount would obtain good treatment quickly after the onset of any sign. Altogether, having regard to the fact that only a very low proportion of cases of the kind under consideration would develop cardio-vascular syphilis, to the life-prolonging effect of good treatment after onset of signs, and to the mean age at death from cardio-vascular syphilis being about 60 in any case, it seems reasonable to estimate that the chances of a proposer who has been treated as mentioned dying of syphilis before the age of 60 average about nil.

(3) The case treated in the early stages with about half the amount of treatment now advised but with negative blood and fluid more than four years after infection. I 


\section{BRITISH JOURNAL OF VENEREAL DISEASES}

believe that the average case of this kind would not die of syphilis before the age of 60 and would therefore suggest that payment of his premiums ought to be completed by this age.

(4) The proposer treated as in (I), (2) and (3) who was infected less than four years ago. I suggest either postponing acceptance until the four years have elapsed, or heavier premiums at first, subject to review on production of evidence that blood and spinal fluid are negative at the end of four years.

(5) The proposer with positive blood four or more years after infection is a much more difficult case. I suggest that, unless he can prove that his spinal fluid is completely negative, he should be regarded as a bad risk. If, on the other hand, the spinal fluid is negative, practically the only risk is of death from cardio-vascular syphilis, and an average case of this kind would not die of it before the age of 60 .

One could go on almost indefinitely considering variations of the above five types but they seem sufficient for purposes of discussion. I should like to repeat that they have been presented in this way not in any dogmatic spirit but as a basis of discussion. You who look at the problem from another angle will doubtless find many flaws in my suggestions but in doing so we may perhaps get nearer to a rational practice in respect of the assessment of the syphilitic proposer's premiums. An eminent American syphilologist to whom I wrote for a reference for purposes of this address ended his reply wishing me " the very greatest success to gain a more intelligent attitude on the part of Life Assurance Companies toward the disease, syphilis."

\section{REFERENCES}

Batchelor, R. C. L. \& Lees, R. (I939) Brit. med. J., ii, IoI7.

Bruusgaard, E. (I929) Arch. Derm. Syph. Wien., 157, 309.

Cole, H. N. with Usilton, L. J. \& Moore, J. E., O'Leary, P. A., Stokes, J. H., Wile, U. J., Parran, T., Jr. \& VonderLEHR, R. A. (1936) Vener. Dis. Inform., 17, 91 ; (I937) J. Amer. med. Ass., 108, I86r.

DattneR, B. “Moderne Therapie der Neurosyphilis," Wien, I933,

Grant, R. T. (r933) Heart, 16, 275.

W. Maudrich, p. I39.

Madden, J. F. (I930) Amer. J. Syph., 14, 45I.

Meagher, E. T. (I929) Board of Control. "General Paralysis and its Treatment by Induced Malaria," H.M.S.O. 
Moore, J. E. \& Cole, H. N., O'Leary, P. A., Stokes, J. H., Wile, U. J., Clark, T., Parran, T. \& Usilton, L. J. (I932) Vener. Dis. Inform., 13, $37 \mathrm{I}$.

Moore, J. E., Danglade, J. H. \& Reisinger, J. C. (I932) Arch. intern. Med., 49, 879 .

Müller-Dehan, A. (I928) Dtsch. med. Wschr., 54, 2 I 44.

NiCOL, W. D. (1932) J. ment. Sci., 78, 843.

Norris, C. B. (I930) Arch. Derm. Syph. N.Y., 21, 985.

O'Leary, P. A. \& Rogin, J. R. (I932) Arch. Derm. Syph. N.Y., 26, 783.

O'Leary, P. A. \& Welsh, A. L. (I933) J. Amer. med. Ass., 101, 498. PADGET, P. \& Moore, J. E. (I935) Amer. Heart J., 10, IoI7.

Sinton, J. A. (I938) Bull. Off. int. Hyg. publ., 30, 953.

Smith, D. C. \& Kimbrough, R. D. (I928) Sth. med. J., 21, 634.

Srodgrass, W. R. \& Peters, R. J. (I937) “ An Analysis of the Results of Treatment of Early, Latent, and Mucocutaneous Tertiary Syphilis." Medical Research Council Special Report Series, No. 224, p. 62, H.M.S.O.

Stokes, J. H. with Usilton, L. J. \& Cole, H. N., Moore, J. E., O'Leary, P. A., Wile, U. J., Parran, T., Jr., McMullen, J. (r934) Vener. Dis. Inform., 15, 34I.

Strandberg, J. (I937) Brit. J. vener. Dis., 13, I77.

Thompson, W. P., Comeau, W. J. \& White, P. D. (1939) Amer. Heart J., 17, 286.

Vonderlehr, R. A. \& Usilton, L. J. (I938) Vener. Dis. Inform., 19,

WALKER, K. (I936) Brit. J. vener. Dis., 12, 43. 396.

Weatherby, F. E. (r929) Amer. J. Syph., 13, 339. 